\title{
Brain tumor with an ATXN1-NUTM1 fusion gene expands the histologic spectrum of NUTM1-rearranged neoplasia
}

\author{
Aurore Siegfried ${ }^{1,2}$, Julien Masliah-Planchon ${ }^{3,4}$, Franck-Emmanuel Roux ${ }^{1}$, Delphine Larrieu-Ciron ${ }^{1}$, Gaelle Pierron ${ }^{5}$, \\ Yvan Nicaise ${ }^{2}$, Marion Gambart ${ }^{1}$, Isabelle Catalaa ${ }^{1}$, Sarah Péricart ${ }^{1}$, Charlotte Dubucs ${ }^{1}$, \\ Badreddine Mohand-Oumoussa ${ }^{6}$, Franck Tirode ${ }^{7}$, Franck Bourdeaut ${ }^{3,4}$ and Emmanuelle Uro-Coste ${ }^{1,2^{*}}$ (D)
}

Keywords: NUTM1, ATXN1, NUTM1-rearranged neoplasia, RNA sequencing, DNA methylation-based classification, Central nervous system, Oncogenic gene fusions, CIC-ATXN1-ATXN1L axis

We report a novel ATXN1-NUTM1 gene fusion in a primitive brain tumor (Fig 1a). A 21-year-old woman was seen in an emergency department for symptoms of increased intracranial pressure, visual disturbance and right hemiparesis. She reported unusual headaches for the past 3 weeks. MRI showed a frontal tumor with intratumoral hemorrhage (Fig. 1b). The entire tumor was surgically removed. The patient did not receive any additional treatment. 16 months after surgery, the patient was symptom-free and MRI showed no recurrence of the tumor.

Histological features were characterized by a fascicular architectural pattern and chondro-myxoid areas (Fig. 1c, d, e, f). Neuron-like tumor cells were apparent (Fig. 1c). Mitotic activity was overall low but increased in some foci (Fig. 1d). Strong GFAP staining led to an initial diagnosis of an unclassified glioneuronal tumor in spite of olig2 and PS100 negativity (Fig. 1g). Microscopically, the tumor was well circumscribed (Fig. 1h). p53 was accumulated (Fig. 1i). CD56 was strongly expressed. TTF1, chromogranin, synaptophysin, CD34, p63, CK5/6 and smooth muscle actin were negative. ATRX, INI1 and BRG1 expression was maintained. Using the Heidelberg DNA methylation-based CNS tumor classifier, no class prediction was obtained with a greater than $\geq 0.9$ confidence threshold [1]. The closest entity was the CNS

\footnotetext{
* Correspondence: uro-coste.e@chu-toulouse.fr

'Departments of Pathology, Neurology, Neurosurgery, Radiology and Pediatric Oncology, Toulouse University Hospital, Toulouse, France ${ }^{2}$ INSERM U1037, Cancer Research Center of Toulouse (CRCT), Toulouse, France

Full list of author information is available at the end of the article
}

Ewing Family Tumor CIC group with a score of 0.235 (Additional file 1: Table S1) (Case methylation data: http:// www.ncbi.nlm.nih.gov/geo; GSE138550). This tumor group is associated to the CIC-NUTM1 gene fusion [6]. We observed strong homogeneous nuclear staining with an antiNUT antibody, suggesting the presence of a CIC-NUTM1 fusion (Fig. 1j). RNA sequencing using the Illumina TruSight RNA Fusion panel and Manta for fusion calling revealed a novel ATXN1-NUTM1 fusion. A CIC-NUTM1 fusion was not detected. ETV4 was overexpressed as in CIC-fused sarcomas [4, 6]. No pathogenic variants were observed in tumor DNA using a 571-gene targeted sequencing panel (Additional file 2: Table S2).

The fusion gene transcript encompassed almost all of the ATXN1 coding sequence and the entire exon 6, 7 and 8 regions of NUTM1. The most common NUTM1 breakpoints map between exon 1 and 2, but breakpoints at the distal end of exon 5 have also been described in some CIC-NUTM1 sarcomas [4].

Initially associated with NUT midline carcinomas, NUTM1 fusions have now been described in a broad spectrum of tumors ranging from carcinoma to sarcoma and leukemia $[2,3,7]$. The most common fusion partner gene in carcinoma and sarcoma is BRD4 followed by $B R D 3$ and NSD3. Various new partners have been recently described $[2,3,5]$. The prognosis of these tumors is generally poor, although NUT-associated leukemias appear to be associated with a better prognosis and YAP1-NUTM1 is associated with benign skin adnexal gland tumors $[3,5]$.

(C) The Author(s). 2019 Open Access This article is distributed under the terms of the Creative Commons Attribution 4.0 International License (http://creativecommons.org/licenses/by/4.0/), which permits unrestricted use, distribution, and reproduction in any medium, provided you give appropriate credit to the original author(s) and the source, provide a link to the Creative Commons license, and indicate if changes were made. The Creative Commons Public Domain Dedication waiver (http://creativecommons.org/publicdomain/zero/1.0/) applies to the data made available in this article, unless otherwise stated. 

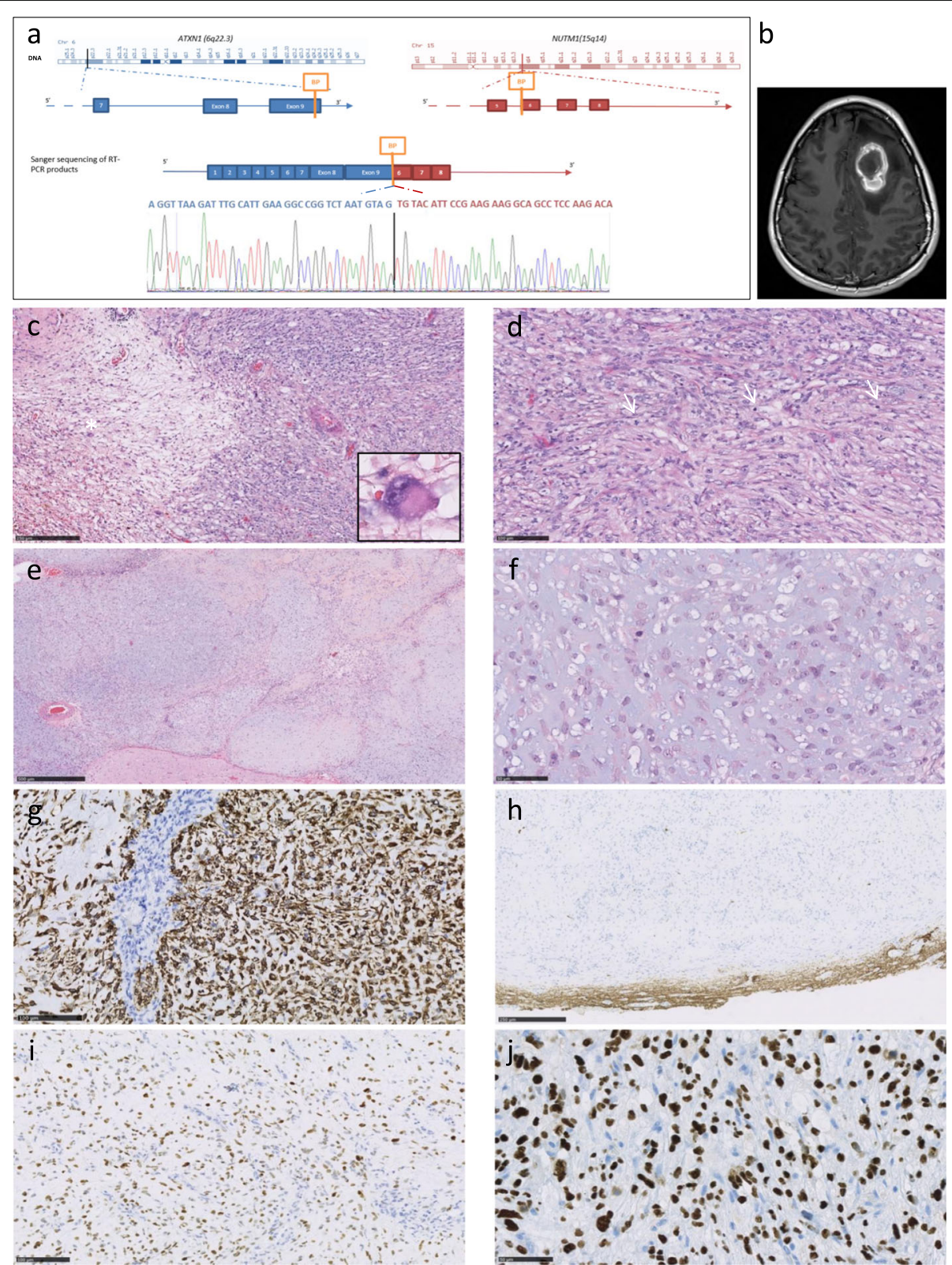

Fig. 1 ATXN1-NUTM1 gene fusion, confirmed by RT-PCR and Sanger sequencing (a). MRI identified a frontal mass. Enhancement after contrast injection (T1) (b). Representative histopathology. On the left, loose area with neuron-like tumor cells (*detail). On the right, increase in cell density (c). Fascicular architecture with three mitoses (arrows) (d). Chondroid-like, myxoid and hyalinized areas were observed (e). Undifferentiated cells with large nucleoli in a chondromyxoid background (f). Strong GFAP staining was observed. Tumor showed vascular proliferation (g).

Neurofilament staining circumscribed the tumor mass with no significant staining within the tumor (h). p53 accumulated in tumor nuclei (i). AntiNUT antibody staining showing homogeneous intranuclear expression (j)

CIC rearranged sarcomas are often fused to DUX4 and less frequently to NUTM1 [4, 7]. All CIC re-arranged tumors irrespective of their location or their fusion partner gene share the same transcriptomic profile defining a molecular subgroup distinct from NUT carcinoma [4, 7]. Interestingly, ATXN1 codes for ataxin1 which forms a transcriptional repressor complex with CIC. They are both part of the CIC-ATXN1-ATXN1L mitotic cell cycle regulator axis [8]. Excluding CIC-NUTM1 fused tumors, only one NUTM1 rearranged brain tumor has been previously reported, namely a cytokeratin negative BRD4-NUTM1 PNET-like parietal lobe tumor in a 3year old boy with GFAP and synaptophysin positivity. On methylation profiling, this neoplasm did not cluster with tumors of the CNS Ewing Family Tumor CIC group [2]. 
Myxoid and chondroid differentiation has been reported in NUTM1-rearranged sarcomas but is unusual in primary glioneuronal tumors. Whether the strong GFAP positivity of our specific case is indicative of a glial tumor or of a sarcoma with myoepithelial differentiation cannot be assessed due to the lack of positive staining and specificity for other markers tested. GFAP positivity has been described in 3 out of 4 NUTM1 rearranged soft tissue or visceral sarcomas, this is in contrast to the CNS Ewing Family Tumor CIC group which fails to express any differentiation markers $[2,6]$. We recommend performing NUT immunohistochemistry followed by RNA sequencing to identify any potential NUTM1 fusion partner genes in GFAP+/olig2- unclassified glioma, particularly those with myxoid and/or chondroid features. The ATXN1-NUTM1 fusion gene may define a novel group of rare primary brain tumors. The prognostic influence of NUTM1 fusion partners and the brain localization of NUTM1-rearranged tumors warrant further investigation.

\section{Supplementary information}

Supplementary information accompanies this paper at https://doi.org/10 1186/s40478-019-0870-8.

Additional file 1: Table S1. Results of the Heidelberg DNA

methylation-based CNS tumor classifier (entities and scores).

Additional file 2: Table S2. List of the 517 childhood cancer genes in the dragon targeted gene sequencing panel (IIlumina_TruSeq Custom Amplicon).
Received: 11 December 2019 Accepted: 11 December 2019

Published online: 30 December 2019

References

1. Capper D, Jones DTW, Sill M et al (2018) DNA methylation-based classification of central nervous system tumours. Nature 555:469-474

2. Dickson BC, Sung YS, Rosenblum MK, Reuter VE, Harb M, Wunder JS, Swanson D, Antonescu CR (2018) NUTM1 gene fusions characterize a subset of undifferentiated soft tissue and visceral tumors. Am J Surg Pathol 42:636-645

3. Hormann FM, Hoogkamer AQ, Beverloo HB et al. (2019) NUTM1 is a recurrent fusion gene partner in B cell precursor acute lymphoblastic leukemia associated with increased expression of genes on chromosome band 10p12.31-12.2. Haematologica. [ahead of print] PubMed PMID: 30872366

4. Le Loarer F, Pissaloux D, Watson S et al (2019) Clinicopathologic features of CIC-NUTM1 sarcomas, a new molecular variant of the family of CIC-fused sarcomas. Am J Surg Pathol 43:268-276

5. Sekine S, Kiyono T, Ryo E et al (2019) Recurrent YAP1-MAML2 and YAP1NUTM1 fusions in poroma and porocarcinoma. J Clin Invest 130:3827-3832

6. Sturm D, Orr BA, Toprak UH et al (2016) New brain tumor entities emerge from molecular classification of CNS-PNETs. Cell. 164:1060-1072

7. Watson S, Perrin V, Guillemot D et al (2018) Transcriptomic definition of molecular subgroups of small round cell sarcomas. J Pathol 245:29-40

8. Wong D, Lounsbury K, Lum A et al (2019) Transcriptomic analysis of CIC and ATXN1L reveal a functional relationship exploited by cancer. Oncogene 38 : 273-290

\section{Publisher's Note}

Springer Nature remains neutral with regard to jurisdictional claims in published maps and institutional affiliations.

\section{Acknowledgments}

Samples were obtained from the CHU de Toulouse tumor bank BB-003300014. We thank the "Société Française des Cancers de l'Enfant" for their support.

\section{Authors' contributions}

$A S, F T, F B, E U C$ were major contributors in writing the manuscript. JMP, GP YN, BMO carried out the molecular genetic studies. AS, SP, EUC characterized the histological features. YN, CD carried out the sequence alignment. FER, DLC, MG, IC contributed to the data collection. All authors read and approved the final manuscript.

\section{Competing interests}

The authors declare that they have no competing interests.

\section{Author details}

'Departments of Pathology, Neurology, Neurosurgery, Radiology and Pediatric Oncology, Toulouse University Hospital, Toulouse, France. ${ }^{2}$ INSERM U1037. Cancer Research Center of Toulouse (CRCT), Toulouse, France. ${ }^{3}$ Departments of Genetics and of Oncopediatry and Young Adults, Curie Institute, Paris, France. ${ }^{4}$ INSERM U830, Laboratory of Translational Research in Pediatric Oncology, SIREDO pediatric oncology center, Curie Institute, Paris, France. ${ }^{5}$ Department of Somatic Genetics, Curie Institute, Paris, France. ${ }^{6}$ Plateforme Post-génomique P3S, Faculté de Médecine Pierre et Marie Curie, Paris, France. ${ }^{7}$ INSERM 1052, CNRS 5286, Cancer Research Center of Lyon, Centre Léon Bérard, Claude Bernard Lyon 1 University, Lyon, France.

Ready to submit your research? Choose BMC and benefit from:

- fast, convenient online submission

- thorough peer review by experienced researchers in your field

- rapid publication on acceptance

- support for research data, including large and complex data types

- gold Open Access which fosters wider collaboration and increased citations

- maximum visibility for your research: over $100 \mathrm{M}$ website views per year

At $\mathrm{BMC}$, research is always in progress.

Learn more biomedcentral.com/submissions 